\title{
After Action Report: Advanced Test Reactor Complex \\ 2015 Evaluated Drill October 6, 2015
}

November 2015

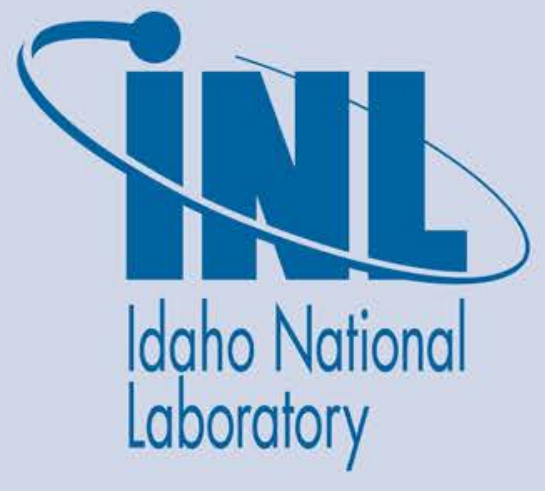

The INL is a U.S. Department of Energy National Laboratory operated by Battelle Energy Alliance 


\section{DISCLAIMER}

This information was prepared as an account of work sponsored by an agency of the U.S. Government. Neither the U.S. Government nor any agency thereof, nor any of their employees, makes any warranty, expressed or implied, or assumes any legal liability or responsibility for the accuracy, completeness, or usefulness, of any information, apparatus, product, or process disclosed, or represents that its use would not infringe privately owned rights. References herein to any specific commercial product, process, or service by trade name, trade mark, manufacturer, or otherwise, does not necessarily constitute or imply its endorsement, recommendation, or favoring by the U.S. Government or any agency thereof. The views and opinions of authors expressed herein do not necessarily state or reflect those of the U.S. Government or any agency thereof. 


\section{After Action Report: Advanced Test Reactor Complex 2015 Evaluated Drill October 6, 2015}

November 2015

Idaho National Laboratory Idaho Falls, Idaho 83415

http://www.inl.gov

Prepared for the U.S. Department of Energy Under DOE Idaho Operations Office

Contract DE-AC07-05ID14517 
This page intentionally left blank. 
Emergency Management

\section{After Action Report: Advanced Test Reactor Complex 2015 Evaluated Drill October 6, 2015}

INL/EXT-15-37173

Revision 0

November 2015

Submitted by

Date

Drill Director

Approved by Carl Farmer

Date

INL Emergency Management Manager 
This page intentionally left blank. 


\section{CONTENTS}

ACRONYMS

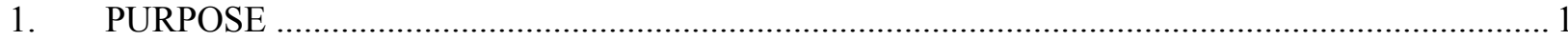

2. SCOPE

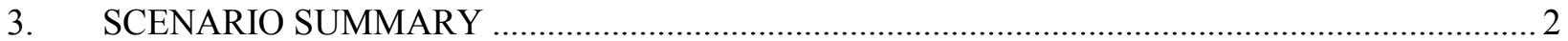

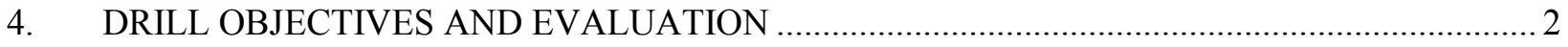

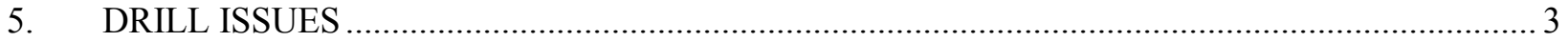

5.1 Emergency Response Organization Response ................................................................ 3

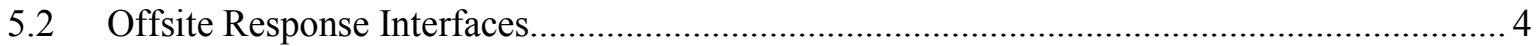

5.3 Emergency Event Categorization and Classification ................................................... 4

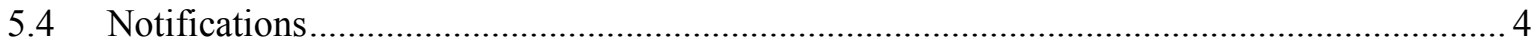

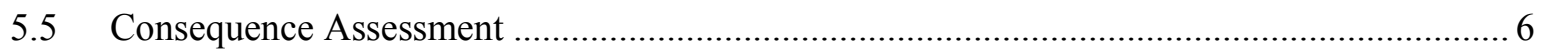

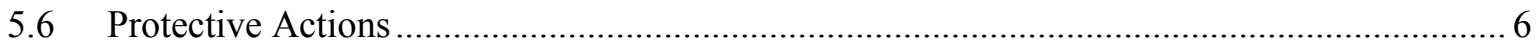

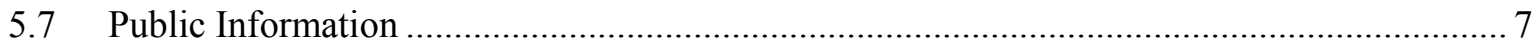

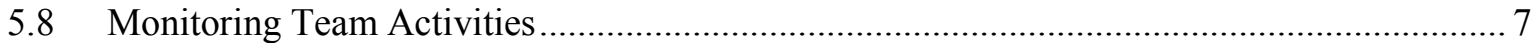

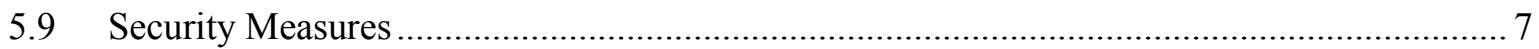

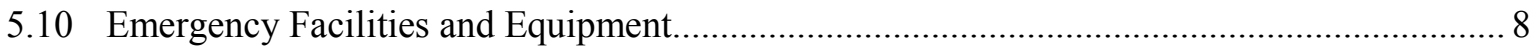

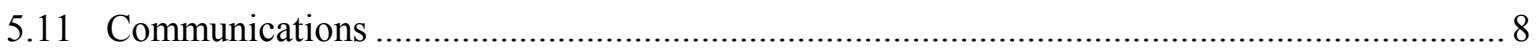

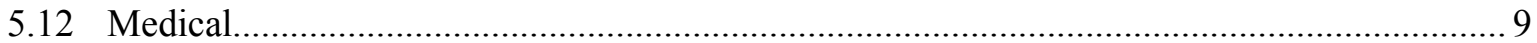

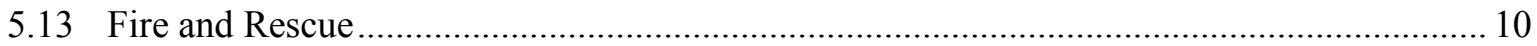

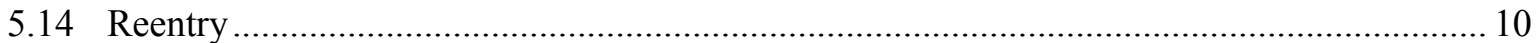

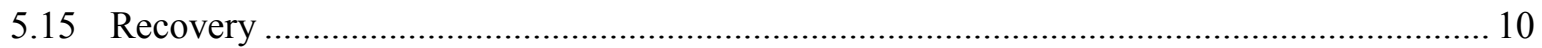

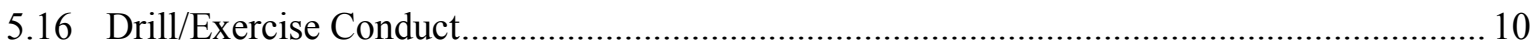

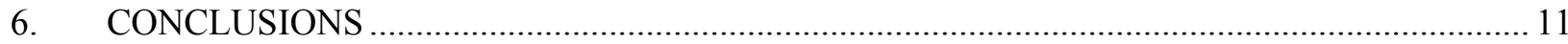

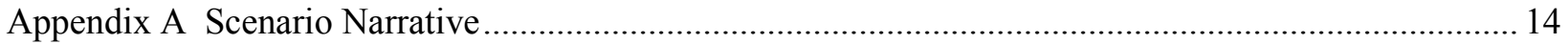

TABLES

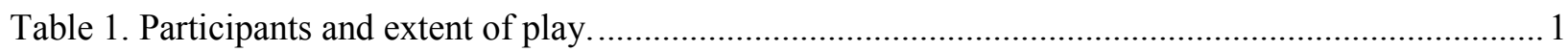

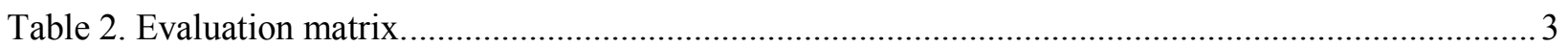




\section{ACRONYMS}

ATR

Advanced Test Reactor

CFA Central Facilities Area

EAL emergency action level

EAM emergency action manager

ECC emergency control center

ED emergency director

EOC emergency operations center

ERO emergency response organization

FAC fire alarm center

FD fire department

IC incident command

INL Idaho National Laboratory

PAL personnel accountability leader

PAs protective actions

$\mathrm{PF} \quad$ protective force

UPS uninterruptible power supply

SAE site area emergency

SNF spent nuclear fuel

SS shift supervisor

WCC Warning Communications Center 
This page intentionally left blank. 


\section{After Action Report: Advanced Test Reactor Complex 2015 Evaluated Drill October 06, 2015}

1. PURPOSE

The Advanced Test Reactor (ATR) Complex, operated by Battelle Energy Alliance, LLC, at the Idaho National Laboratory (INL) conducted an evaluated drill on October 6, 2015, to allow the ATR Complex emergency response organization (ERO) to demonstrate the ability to respond to and mitigate an emergency by implementing the requirements of DOE O 151.1C, "Comprehensive Emergency Management System.”

\section{SCOPE}

Participants and their extent of play are shown in Table 1.

Table 1. Participants and extent of play.

\begin{tabular}{|c|c|}
\hline Participants & Extent of Play \\
\hline \multicolumn{2}{|c|}{ INL Organizations } \\
\hline $\begin{array}{l}\text { ATR Complex Emergency Control Center (ECC) } \\
\text { and facility support personnel }\end{array}$ & Full participation \\
\hline Central Facilities Area (CFA) ECC & Limited: Control cell \\
\hline INL Bus Operations & Full participation \\
\hline INL Emergency Operations Center (EOC) & Full participation \\
\hline INL Fire Alarm Center (FAC) & Limited: Control cell \\
\hline INL Fire Department (FD) & Limited: Control cell \\
\hline Security & Limited: Control cell \\
\hline Joint Information Center (JIC) & Simulated (if requested) \\
\hline Occupational Medicine & Simulated (if requested) \\
\hline Site Monitoring Team (SMT) & Simulated (if requested) \\
\hline Warning Communications Center (WCC) & Full participation \\
\hline \multicolumn{2}{|c|}{ Contiguous Counties } \\
\hline Bingham & Limited: Notifications only \\
\hline Bonneville & Limited: Notifications only \\
\hline Butte & Limited: Notifications only \\
\hline Clark & Limited: Notifications only \\
\hline Jefferson & Limited: Notifications only \\
\hline
\end{tabular}




\begin{tabular}{|l|l|}
\hline \multicolumn{2}{|c|}{ Federal Agencies } \\
\hline DOE-ID & \multicolumn{1}{|c|}{ Full participation } \\
\hline Idaho State Communications Center & State of Idaho Agencies \\
\hline Idaho State Police & Limited: Notifications and communications \\
\hline Idaho Radiation Control Program & Limited: Notifications only \\
\hline INL Oversight Program & Limited: Communications only \\
\hline \multicolumn{2}{|c|}{ Tribal Authority } \\
\hline Shoshone/Bannock Tribe & Limited: Notifications only \\
\hline
\end{tabular}

\section{SCENARIO SUMMARY}

The ATR Complex was in an outage status in accordance with the ATR Integrated Strategic Operational Plan. A 634-Watt Spent Nuclear Fuel (SNF) shipment was on the schedule to move from the ATR Complex to the Idaho Nuclear Technology and Engineering Center (INTEC). The following was simulated as happening: A SNF shipment scheduled to go from ATR Complex to INTEC was involved in a vehicle accident with a dump truck. The collision occurred at the intersection of Perch Street and Sword Fish Boulevard inside the ATR Complex. During the collision, the SNF shipment trailer tipped on its side, causing the shipment cask lid bolts to shear and the lid to become dislodged. The driver of the dump truck, who was still in the cab of the truck, suffers a concussion but is otherwise uninjured and was not contaminated. The driver of the SNF transport vehicle had minor injuries and was able to escape from the cab of the truck.

\section{DRILL OBJECTIVES AND EVALUATION}

During the drill, 10 of the 16 standardized INL objectives were evaluated for the ATR Complex using the appropriate demonstration criteria. All 10 objectives were rated satisfactory or satisfactory with improvement needed.

The ratings in Table 2 are based on the issues that follow in Section 5 of this report. 
Table 2. Evaluation matrix.

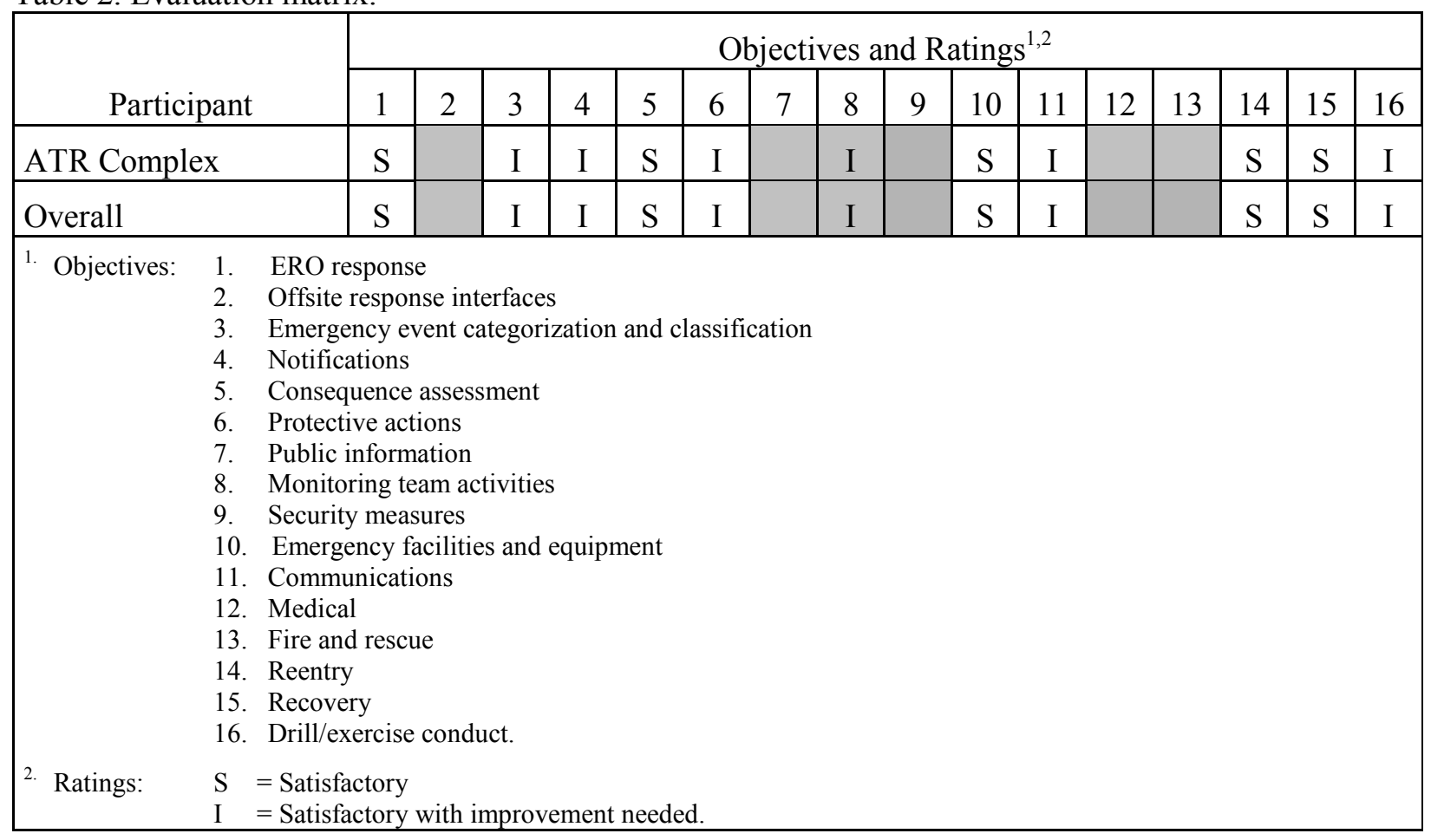

\section{DRILL ISSUES}

The following issues are specific to the evaluation of ATR Complex. Each item has been evaluated and entered into the appropriate issues management system.

\subsection{Emergency Response Organization Response}

Given the facility procedures/plan, the ERO will respond to, monitor, and evaluate the specific indicators of an emergency for mitigation of the consequences and bring the emergency situation under control.

\section{Discussion}

The drill was initiated at 0800 in the ATR simulator. Activation of the ERO began with a voicepaging announcement made from the ATR simulator at 0804 followed by a phone call to the WCC at 0811. Responders to the drill utilized position specific ERO checklists and emergency plan implementing procedures to respond to the simulated event.

WCC did not activate the correct ERO groups using the correct pathways. This precluded ERO members receiving notification at a desk phone from receiving the notification. A change in the Everbridge software used to activate the ERO has precluded a reoccurrence of this.

ATR Complex protective force (PF) personnel were not available to respond to the ATR Complex ECC because of other assignments. During the drill, the EOC was unable to contact a security representative in the ATR Complex ECC.

Engineering department personnel responding to the ECC as part of the Planning Team and Recovery Team expressed a desire to have a list of personnel, based on engineering disciplines that could be called upon to provide technical support and participate in drills and events. 
Issues

- 5.1.1: Lack of available ATR Complex security personnel in the ECC and the operation of security camera images.

Recommendation 5.1.1.1: INL security needs to address the availability of personnel to respond to the ATR Complex ECC to allow for communicating security related information to the EOC from the ATR Complex ECC. Laboratory Protection LabWay No. LP-CO-2015-1932 assigned.

Recommendation 5.1.1.2: A formal resolution needs to be provided to allow projecting security camera images in the ATR Complex ECC. Laboratory Protection LabWay No. LP-CO-2015-1933 assigned.

- 5.1.2: Engineering department personnel that responded to the ATR Complex ECC expressed the need of a list of personnel that could be called upon to provide technical support during drills and emergencies.

Recommendation 5.1.2.1: ATR Complex engineering needs to identify personnel in specific engineering disciplines to respond to the ECC during drills and emergencies. ATR Complex

LabWay No. CO-2015-4183 assigned.

\subsection{Offsite Response Interfaces}

Given the facility procedures/plan, the ERO will coordinate and interface with response organizations to protect the environment and health and safety of the public.

Issues

- Not evaluated.

\subsection{Emergency Event Categorization and Classification}

Given the facility procedures/plan, the ERO will accurately and promptly categorize and classify the operational emergency.

\section{Discussion}

The drill was initiated at 0800 in the ATR simulator. The ATR shift supervisor (SS) in the ATR simulator correctly categorized and classified the event as a site area emergency (SAE) using emergency action level (EAL) ATR-TRN-3.SAE.4 at 0810. Emergency notifications were initiated based on this classification. At 0836, the emergency action manager (EAM) in the ATR Complex ECC accepted categorization and classification responsibility from the ATR simulator SS. A second SAE (ATR-TRN4.SAE.1) was declared at 0930 when information regarding the spill of diesel fuel was reported to the ATR Complex ECC from the event scene. This second EAL was declared subsequent to a discussion with the DOE facility representative. After the responsibility of making notifications had been transferred to the emergency director (ED), an additional notification form was filled out in the ATR Complex ECC.

The EAM communicated with the ED and it was decided the ATR Complex ECC would do the notification with the new EAL instead of the ED. This is not in accordance with EPI-15, "ATR Complex Operational Emergency Categorization/Classification and Protective Actions," or EPI-9, "Emergency Event Notifications.

\section{Issues}

- 5.3.1: Transfer of categorization and classification was not clearly understood in the ATR Complex ECC and the EOC. 
Recommendation 5.3.1.1: ATR Complex ECC EAMs and support managers should receive training during a tabletop drill to correct this misunderstanding. ATR Complex LabWay No. CO-2015-4185 assigned.

Recommendation 5.3.1.2: EOC EDs and support directors should receive lessons learned clarifying the transfer of categorization and classification responsibilities. Laboratory Protection LabWay No. LP-CO-2015-1934 assigned.

\subsection{Notifications}

Given the facility procedures/plan, the ERO will report emergencies and conduct follow-up notifications to the appropriate organizations within the required time.

\section{$\underline{\text { Discussion }}$}

The initial emergency notification was initiated in the ATR simulator by the simulator SS. A SAE was declared at 0810 . The initial notification form was faxed to the WCC at 0816 . The WCC called the simulator SS and asked what they were to do with the notification form. The initial notification was completed at 0827 missing the 15 minutes time frame. At 0836, the EAM in the ATR Complex ECC accepted notification responsibility from the ATR simulator SS. The second notification form was faxed to the WCC at 0858 and WCC completed the notification at 0911 . Notification responsibility was transferred to the ED at 0917. A third notification was initiated in the ATR Complex ECC to address an additional SAE EAL declaration triggered by the report of a diesel fuel spill at the scene. The EAM discussed this new report with the ED and with concurrence from the ED, the EAM initiated transmittal of notification \#3. Notification \#3 was faxed to the WCC from the ATR Complex ECC at 0937 and was completed by WCC at 0950 . Because the responsibility of notifications was transferred to the ED at 0917 , the third notification should have been issued from the EOC. A termination notification was not completed by the EOC.

\section{Issues:}

- 5.4.1: The WCC failed to complete the initial notification in the timeframe required. The notification form was transmitted to the WCC at 0816 . The notification was not completed until 0827 . The delay in completing the notification was due to personnel performing the notification being unfamiliar with the process.

Recommendation 5.4.1.1: WCC personnel should receive formal training on the notification process. Laboratory Protection LabWay No. LP-CO-2015-1935 assigned.

- 5.4.2: The third notification, transmitted from the ECC after responsibility had been transferred to the ED was not in accordance with EPI-9. Additionally, there appeared to have been uncertainty and confusion over who owned notifications after the transfer to the ED was completed.

Recommendation 5.4.2.1: ATR Complex ECC EAMs and support managers should receive training during a tabletop drill to clarify the responsibilities for the correct transfer of notifications. ATR Complex LabWay No. CO-2015-4187 assigned.

Recommendation 5.4.2.2: EOC EDs and support directors should receive lessons learned clarifying the responsibilities for correct transfer of notifications. Laboratory Protection LabWay No. LPCO-2015-0274 assigned.

- 5.4.3: The third notification form captured the time for declaration of the second SAE EAL. EPI-9, EPI-15, and form 150.06A, "Idaho National Laboratory Follow-up Emergency Notification Form," do not provide guidance on how to capture the time additional EALs are declared. 
Recommendation 5.4.3.1: Review/revise EPI-15, EPI-9, and form 150.06A to provide clarification on how to properly capture additional EALs identified during an emergency on the notification form. Laboratory Protection LabWay No. LP-CO-2015-1936 assigned.

- 5.4.4: A termination notification is required by EPI-9. A termination notification was not completed by the EOC.

Recommendation 5.4.4.1: Review EPI-9 with EAMs, ED's, support manager, and support directors with an emphasis for responsibility to complete a termination notification. Laboratory Protection LabWay No. LP-CO-2015-0275 assigned.

\subsection{Consequence Assessment}

Given the facility procedures/plan, the ERO will assess actual and potential onsite and offsite consequences of an emergency.

\section{$\underline{\text { Discussion }}$}

Consequence assessment activities were initiated in the ECC in a timely manner. Two consequence assessment data forms were submitted from the ECC. The first was transmitted at 0843. A second form was faxed at 0913 and again at 0922. Radiation surveys to assess habitability of the ECC were quickly initiated by radiological controls. Levels of $350 \mathrm{mr} / \mathrm{hr}$ were reported to the EAM. This initiated actions to relocate the ECC to CFA. As part of the conduct of the drill, participants were directed to ignore the radiation levels and to continue drill play as if radiation levels were $<0.1 \mathrm{mr} / \mathrm{hr}$. Facility monitoring activities were well integrated with consequence assessment activities during the course of the drill. A consequence assessment form should have been submitted when the spill of diesel fuel was reported to the ECC. While this information was shared with the EOC on the planning and command bridges, no form was submitted.

During the drill response in the EOC, there was confusion on the responsibility for activating the NOAA meteorological monitoring tower radiation monitors. Checklists for two positions state they have that responsibility. Responders were confused as to who should have activated the monitors.

\section{Issues}

- 5.5.1: No consequence assessment data form was submitted detailing the information regarding the diesel spill.

Recommendation 5.5.1.1: Review EPI-50, "Initial Radiological and Nonradiological Consequence Assessment for Emergency Control Center," with ATR Complex ECC planning managers and radiological engineering technical support personnel during a tabletop drill. Laboratory Protection LabWay No. LP-CO-2015-4188 assigned.

- 5.5.2: Activation of the radiation monitoring instrumentation on the NOAA towers is tasked to two personnel in the EOC. This causes confusion among the responders in the EOC.

Recommendation 5.5.2.1: Review and revise EOC checklists to resolve this conflict. Laboratory Protection LabWay No. LP-CO-2015-1937 assigned.

\subsection{Protective Actions}

Given the facility procedures/plan, the ERO will respond to emergency conditions to protect onsite personnel and the public by implementing specific, predetermined actions.

\section{Discussion}

The ATR simulator SS categorized the event as an SAE at 0810. Siren initiation was accomplished by the ATR control room at 0810 . Sirens were initiated without specific direction being given by the ATR 
simulator SS. This will be addressed in the drill conduct element of this report. Personnel exited the ATR complex in a timely manner with the last person out of the facility being an area warden 13 minutes after siren initiation. At 0836, the EAM in the ATR Complex ECC accepted notification responsibility from the ATR simulator SS. Protective Actions (PAs) responsibility for outside of ATR Complex was transferred to the ED at 0917.

Accountability was completed in 45 minutes. Numerous problems with drill exemptions significantly delayed completing accountability. This will be addressed in the drill conduct element of this report.

\section{$\underline{\text { Issues }}$}

- $\quad$ No issues identified.

\subsection{Public Information}

Given the facility procedures/plan, the ERO will demonstrate an emergency public information program.

$\underline{\text { Issues }}$

- Not evaluated.

\subsection{Monitoring Team Activities}

Given the facility procedures/plan, the ERO will provide facility/site monitoring teams in support of consequence assessment activities.

Facility monitoring team activities were slow to initiate. The first team deployed at 0925 . Procedure use and monitoring team briefings were thorough. Survey techniques used by the monitoring teams were very good. Assignment of electronic dosimeters with accident level alarm set points was hindered by a problem with operability of the Dosimass computer. While the computer was tested on September 10, 2015, the computer suffered connectivity issues during the drill. Following the drill, the computer worked properly.

Monitoring team personnel used the wrong radios in trying to conduct communication tests. Two types of radios were present in the ATR Complex ECC safety room. The radios do not communicate with each other. Subsequent to the drill, the incompatible radios were removed.

Data capture and display in the ATR Complex ECC and with other organization is not fully effective. Improvements through the use of GPS data and smart boards would improve some aspects of the performance problems. Additionally, integration of drone use should be considered to improve speed of data capture and safety of responders. Use of a Go-Pro style video camera by monitoring teams would also improve information capture and allow for sharing images of the event scene more effectively.

\section{Issues}

- 5.8.1: Facility monitoring team activities were slow to initiate. The monitoring team was delayed because a set of accident response electronic dosimeters is not staged for use in the ATR Complex ECC. Inconsistencies between EPI-55, "ATR Complex Facility Emergency Radiological Monitoring," and ATR-11, "Facility Monitoring Team Coordinator," hindered effective response from the facility monitoring team coordinator and the monitoring teams.

Recommendation 5.8.1.1: The two documents, EPI-55 and ATR-11, should be reconciled. EPI-55 needs to be reviewed to formalize a more effective response and support structure for monitoring team activities. ATR Complex LabWay No. CO-2015-4189 assigned.

- 5.8.2: Facility monitoring data capture and display in the ATR Complex ECC and with other EROs is not fully effective. 
Recommendation 5.8.2.1: Improvements through the use of GPS systems, smart boards, Go-Pro style video cameras, and other remote monitoring systems needs to be evaluated for inclusion in INL facility and site monitoring during operational emergencies. Radiological controls should evaluate opportunities to improve capture and display of data and develop a plan to implement the improvements. INL LabWay No. CO-2015-4190 assigned.

\subsection{Security Measures}

Given the facility procedures/plan, Security will respond to, monitor, and evaluate the specific indicators of an emergency for mitigation of the consequences and bring the emergency situation under control.

Issues

- Not evaluated.

\subsection{Emergency Facilities and Equipment}

Demonstrate the adequacy of facilities, equipment, displays, and other materials to support emergency operations.

\section{Discussion}

The phone used by the ATR simulator SS failed during the drill. Phone was fixed the same day. This phone is not part of the emergency response equipment tested periodically by emergency management.

WebEOC computers crashed when a print was attempted. Immediate testing of the computers to try to replicate this fault failed to reproduce the fault. Subsequent to the drill, a defective uninterruptible power supply (UPS) was found to be the cause of the crash. Need for the UPS was reviewed, and the UPS was removed.

The facility monitoring team coordinator computer was slow. Subsequent to the drill, field services installed a patch that resolved the performance problem. This patch was not part of the normal monthly periodic patches issued by INL Information Technologies.

$\underline{\text { Issues }}$

- No issues identified.

\subsection{Communications}

Communications capabilities are managed in support of emergency operations to ensure prompt and appropriate flow of accurate information during an emergency.

\section{Discussion}

Verbal information exchange between the ATR Complex and the EOC was very good. Briefings from the ATR simulator SS to the ED and the EAM were detailed and timely. Communications of information on the planning bridge were very effective timely and detailed. Command bridge duration was reported as very good by responders. Responders in the ATR simulator and the ATR Complex ECC demonstrated very good conduct of operations techniques.

A back up EAM was used as the command bridge communicator during the drill. This freed up the EAM to manage the event. Lessons learned from other facilities show there are risks and opportunities for adverse impacts from this practice. 
WebEOC entries did not give a detailed picture of events and the status of events. No initial entry from the ATR Complex ECC was made into WebEOC. As such, the reason for the activation and categorization/classification/PAs was not captured and shared in WebEOC.

WebEOC has two locations that indicate a log entry is a significant event. Only one of these actually promotes a log entry for controller review to make a significant event entry in WebEOC.

The WCC transferred a call from the ATR control room to the ED. This initial call should have been transferred to the EOC support director to provide the support director with the necessary information needed to support early event response actions as required by procedure.

The ATR Complex voice paging system failed in the ATR simulator area of TRA-679. This prevented the ATR simulator SS from hearing messages he had request the ATR control room to make.

\section{Issues}

- 5.11.1: A back up EAM was used as the command bridge communicator during the drill.

Recommendation 5.11.1.1: A review of the risks and issuing of a formal policy determination should be accomplished by ATR management to accept the practice and the risks that accompany this practice. ATR Complex LabWay No. CO-2015-4191 assigned.

- 5.11.2: Operation of WebEOC was problematic during the drill. WebEOC has two locations, which indicate a $\log$ entry is a significant event. Only one of these actually promotes a log entry for controller review to make a significant event entry in WebEOC.

Recommendation 5.11.2.1: Review WebEOC entries and practices during a tabletop drill. ATR Complex LabWay No. CO-2015-4192 assigned.

Recommendation 5.11.2.2: The Emergency Management technologies committee will review WebEOC to see if the duplicate significant event entry capability can be removed. Laboratory Protection LabWay No. LP-CO-2015-1947 assigned.

5.11.3: The WCC transferred an initial briefing call from the ATR control room to the ED. This initial call should have been transferred to the EOC support director to provide the support director with the necessary information needed to support early event response actions as required by procedure.

Recommendation 5.11.3.1: WCC should review the process and procedures to ensure proper routing of event information is accomplished. Operators should receive formal training on expectations and procedure requirements. Laboratory Protection LabWay No. LP-CO-2015-1938 assigned.

- 5.11.4: Voice paging messages made by the ATR control room in response to a request for announcements from the ATR simulator SS was not heard in the simulator.

Recommendation 5.11.4.1: ATR Operations needs to review testing of the voice paging system and repair the link to the ATR simulator. ATR Complex LabWay No. CO-2015-4194 assigned.

\subsection{Medical}

Given the facility procedures/plan, medical response personnel will respond to, monitor, and evaluate the specific indicators of an emergency for mitigation of the consequences and bring the emergency situation under control.

\section{$\underline{\text { Issues }}$}

- Not evaluated. 


\subsection{Fire and Rescue}

Given the procedures/plan, fire and rescue responders will respond to an event involving fire or hazardous material, mitigate the consequences, and bring the situation under control.

$\underline{\text { Issues }}$

- Not evaluated.

\subsection{Reentry}

The ERO will demonstrate development and implementation of a reentry plan to include debriefing of the reentry team and proper recordkeeping in accordance with the facility procedures/plan.

\section{Discussion}

At 0924, the logistics manager was assigned responsibilities as recovery manager. A multi-disciplined recovery team was assembled. The recovery team approached reentry and recovery from a combined efforts perspective. Facility monitoring was identified as a need and two facility-monitoring teams were dispatched. Data from the teams was received in the ECC and shared. No problems in recovery were identified.

\section{Issues}

- $\quad$ No issues identified.

\subsection{Recovery}

Given the facility procedures/plan, the ERO will demonstrate recovery planning for an emergency at the affected facility.

\section{$\underline{\text { Discussion }}$}

At 0924, the logistics manager was assigned responsibilities as recovery manager. A multi-disciplined recovery team was assembled. The recovery team approached reentry and recovery from a combined efforts perspective. Facility monitoring was identified as a need and two facility-monitoring teams were dispatched. Data from the teams was received in the ECC and shared. No problems in recovery were identified.

\section{Issues}

- $\quad$ No issues identified.

\subsection{Drill/Exercise Conduct}

Write, conduct, and evaluate a drill/exercise that will emphasize facility-specific emergency events and response activities and minimize the use of generic, nonspecific simulations in accordance with the facility procedures/plan.

\section{Discussion}

The drill scenario postulated a transportation accident involving a spent ATR fuel shipment to the INTEC and a dump truck. Photos of a model of the accident scene were taken to provide responders with a visualization of the scene. Sharing of the photos was a problem in that they would not display on the security camera monitor in the ATR Complex ECC. A work around of sharing the photos with the information management coordinators was not as effective as desired. Additionally, sharing of the scene photos was incomplete in the ATR Complex ECC in that facility radiological controls personnel, who would have been able to view the scene, were not given access to photos. 
Problems with drill exemptions significantly delayed completing accountability. Personnel that were exempted were not accurately transmitted to the personnel accountability leader (PAL). ATR operations personnel self-exempted themselves from participation. Additionally, a list of protective force personnel remaining in the fenced area at the ATR Complex was not provided to the PAL. This significantly slowed the accountability process.

Measuring accountability completion timeliness during a drill is problematic. The artificialities of drill exemptions slow the completion of the process and introduce time delays that would not exist during an actual event with evacuation.

Drill participants conducted a very self-critical assessment of their performance. A brutally honest assessment of performance on the part of all involved at the ATR Complex offers insight into the maturity of the ERO and operations organizations.

Personnel in the EOC attempted to contact security personnel at the ATR Complex. In the drill prebrief, security was not listed as a participating organization.

\section{Issues}

- 5.16.1: Sharing of the photos of the mocked up accident scene was a problem in that they would not display on the security camera monitor in the ATR Complex ECC. Additionally, sharing of the scene photos was incomplete in the ATR Complex ECC in that radiological controls personnel, who would have been able to view the scene, were not given access to photos.

Recommendation 5.16.1.1: The ATR Complex emergency planner should develop a lessons learned covering the problems identified and possible remedies to be shared with other emergency planners. Laboratory Protection LabWay No. LP-CO-2015-1939 assigned.

- 5.16.2: Problems with drill exemptions significantly delayed completing accountability. Personnel that were exempted were not accurately transmitted to the PAL. ATR operations personnel selfexempted themselves from participation. This significantly slowed the accountability process.

Recommendation 5.16.2.1: The ATR Complex emergency planner should revise SP-10.6.1.22, "ATR Complex Emergency Management Program Implementation," to formalize the exemption process. ATR Complex LabWay No. CO-2015-4195 assigned.

- 5.16.3: A list of protective force personnel remaining in the fenced area at the ATR Complex was not provided to the PAL. This significantly delayed completing accountability.

Recommendation 5.16.3.1: ATR Complex post orders should be revised to address the delivering a roster of protective force personnel to the PAL. Laboratory Protection LabWay No. LP-CO-20151942 assigned.

- 5.16.4: Measuring accountability completion timeliness during a drill is problematic. The artificialities of drill exemptions slow the completion of the process. These also introduce time delays that would not exist during an actual event with accompanying evacuation.

Recommendation 5.16.4.1: Emergency Management should review and revise, if necessary, accountability evaluation guidance in GDE-467, "Emergency Management Drills and Exercises." Laboratory Protection LabWay No. LP-CO-2015-1943 assigned.

- 5.16.5: Personnel in the EOC attempted to contact security personnel at the ATR Complex. In the drill pre-brief, security was not listed as a fully participating organization.

Recommendation 5.16.5.1: A reminder to ERO personnel of the importance of reviewing the prebrief prior to participating in drills and exercises should be included in periodic training update materials. Laboratory Protection LabWay No. LP-CO-2015-1944 assigned. 
5.16.6: Sirens were initiated without specific direction being given by the ATR simulator SS.

Recommendation 5.16.6.1: The ATR Complex emergency planner should revise SP-10.6.1.22, "ATR Complex Emergency Management Program Implementation," to formalize the interface between the ATR control room and simulator during drills/exercises. ATR Complex LabWay No. CO-2015-4204.

\section{CONCLUSIONS}

The drill performance was rated as satisfactory with opportunities for improvement. ERO members utilized facility equipment in accordance with procedures. Equipment glitches were over come and communications were facilitated. The conduct of a very self critical event review by the ATR Complex ERO members is indicative of a mature operations organization willing to self identify problems and resolve issues. Issues identified will be tracked for completion in the LabWay system. 
This page intentionally left blank. 
Appendix A

\section{Scenario Narrative}


This page intentionally left blank. 


\section{Appendix A}

\section{Scenario Narrative}

\section{Background}

The ATR Complex is in an outage status in accordance with the ATR Integrated Strategic Operational Plan. A 634-Watt SNF shipment is on the schedule to move from the ATR Complex to INTEC.

\section{$\underline{\text { Start }}$}

The following is simulated as happening: A SNF shipment scheduled to go from ATR Complex to INTEC is involved in a vehicle accident with a dump truck. The collision occurs at the intersection of Perch Street and Sword Fish Boulevard inside the ATR Complex. During the collision, the SNF shipment trailer tips on its side, causing the shipment cask lid bolts to shear and the lid to become dislodged. The driver of the dump truck, who is still in the cab of the truck, suffers a concussion but is otherwise uninjured and is not contaminated. The driver of the SNF transport vehicle has minor injuries and is able to escape from the cab of the truck.

Simulated from the incident command (IC) control cell, the INL PF personnel with the transport contact Post 505 and report the accident. Simultaneously, the transportation job supervisor contacts the WCC and the ATR SS. Both the WCC and Post 505 personnel contact the INL FAC, which dispatches the INL FD. PF personnel control access to the area. ATR Complex incident response team, INL FD, and emergency medical personnel arrive, complete a scene size up, and develop an action plan.

The WCC contacts the ATR Complex SS, the ED, and the support director, and advises them of the situation. A determination is made to activate the ATR Complex ECC, EOC, CFA ECC, and the JIC. (JIC is simulated)

The injured personnel are triaged and treated. Transportation to CFA medical will be simulated.

At the IC control cell, the incident commander may request additional resources, including a radiological control technician to monitor for radiation levels at the scene and for a release to the environment. Engine Company \#1 continues mitigation of the accident and provides any needed cooling of the SNF shipment.

The ATR SS, per his responsibility as an ATR Complex EAM, declares an operational emergency using the EAL ATR-TRN-3.SAE.4. PAs are determined and implemented (evacuate nonessential personnel 478 meters from the accident scene). An evacuation of ATR Complex is initiated along with the deployment of evacuation buses. The ATR SS provides applicable information to the INL Bus Operations personnel to allow them to determine the number of evacuation buses needed and where to relocate the evacuees. Buses are loaded and then employees will be released to return to their normal work activities. The initial emergency notification is completed by the ATR SS.

The ATR Complex ECC is declared operational. The CFA ECC (control cell) is declared operational. The EOC is declared operational and will simulate the JIC as being operational.

The ATR SS transfers ATR Complex EAM responsibilities to the ATR Complex EAM. The ATR Complex EAM provides briefings over the command bridge as needed during the event. 
The ATR Complex PF personnel working with the IC (in the IC control cell) continues to control access to the event area.

The ATR Complex facility monitoring team is deployed to monitor for a release of radioactive material. During monitoring activities, it is determined a release has occurred. Information is provided to the EOC assessment specialist(s) to verify PAs are adequate using applicable plume modeling software.

Environmental notifications are made.

Reentry planning activities occur on how to inspect the cask lid to allow further planning on how to put the cask lid back in place and contain the potential runoff from the SNF cooling.

Categorization/classification, PAs/protective action recommendations, and notification functions may be transferred from the ATR Complex EAM to the ED.

Press releases are developed and approved by the EOC public information director.

The support director periodically should request the WCC make radio announcements about the status of the event.

Consequence assessment activities are conducted in the EOC planning room with results provided to the ATR Complex EAM and the ED.

The WCC receives emergency notification forms throughout the event. Initial notification to offsite agencies will be completed. Follow-up notifications to off-site agencies will be simulated.

When a recovery manager is identified and a reentry plan to inspect the cask lid has been approved, drill termination may be approved by the drill director. 